Pacific Journal of Mathematics

THE PERIPHERALITY OF IRREDUCIBLE ELEMENTS OF
LATTICE 


\title{
THE PERIPHERALITY OF IRREDUCIBLE ELEMENTS OF A LATTICE
}

\author{
J. W. LEA, JR.
}

\begin{abstract}
Irreducible elements, which are not cutpoints, and meet complemented elements are peripheral in certain compact lattices and semilattices.
\end{abstract}

The purpose of this note is to extend the results of A. D. Wallace [12]; i.e., to show that meet irreducible elements and meet complemented elements are peripheral in certain topological lattices and semilattices. Meet irreducible elements have played a key role in embedding theorems for topological lattices obtained by K. A. Baker and A. R. Stralka [2] and by the author [10].

1. Preliminaries. If $S$ is a semilattice and $x \in S$, then $M(x)=$ $\{y \in S: x \leqslant y\} ; L(x)$ is defined dually; if $x \leqslant y$, then

$$
[x, y]=M(x) \cap L(y) \text {. }
$$

An element $x$ in a semilattice $S$ is meet irreducible if $a, b \in S$ and $x=a \wedge b$ imply $x=a$ or $x=b$. We denote the set of all meet irreducible elements of $S$ by $M I(S)$. If $S$ has a 0 , an element $x \in S$ is meet complemented if there is a $y \in S$ such that $y \neq 0$ and $x \wedge y=0$. The width $w(X)$ of a partially ordered set $X$ is the maximum number of elements in a set of incomparable elements.

A topological semilattice $S$ is said to have small semilattices at $x$ if $x$ has a basis of neighborhoods which are subsemilattices of $S$; $S$ is a Lawson semilattice if it has small semilattices at every point.

Basic definitions, notations, and properties of Alexander cohomology and codimension may be found in [11] and [4]. The point $x$ is marginal in a regular space $X$ if and only if for any open set $U$ containing $x$, there exists an open set $V$ containing $x$ and contained in $U$ such that the natural homomorphism $H^{*}(X) \rightarrow H^{*}(X \backslash V)$ is an isomorphism [8, Th. 1.3]. A point $x \in X$, a topological space, is peripheral if for any open set $U$ containing $x$, there exists an open set $V$ containing $x$ and contained in $U$ such that the homomorphism $i^{*}: H^{*}(X, X \backslash V) \rightarrow(X, X \backslash U)$ induced by the inclusion mapping $i$ is the trivial or zero homomorphism. A point is inner if it is not peripheral.

2. Peripheral elements. J. D. Lawson and B. Madison [9, Th. 3.2] have proved that cutpoints of compact, connected spaces are 
inner points. This result and Theorem 2.1 locate all the meet irreducible elements of a semilattice.

THEOREM 2.1. Let $S$ be a compact, connected, locally connected Lawson semilattice. If $p \in S$ is meet irreducible and is not a cutpoint of $S$, then $p$ is marginal in $S$.

Proof. Let $p \in U$, an open subset of $S$. Since $p$ is not a cutpoint of $S$, it is known [14, III 4.15] that there exists an open set $V$ containing $p$ such that $V \subset U$ and $S \backslash V$ is connected. If

$$
x, y \in S \backslash\{p\},
$$

then $x \wedge y \in S \backslash\{p\}$ because $p$ is meet irreducible. Thus $S \backslash\{p\}$ is a locally compact Lawson semilattice. Hence there exists a compact subsemilattice $W \subset S \backslash\{p\}$ such that $S \backslash V \subset W$ [6, Lemma 5.2]. Since $S \backslash V$ is connected, the closed semilattice $B$ generated by $S \backslash V$ is a compact, connected subsemilattice of $W ; B$ is acyclic [13]; thus $H^{*}(S) \rightarrow H^{*}(B)$ is an isomorphism. Since $S \backslash V \subset B \subset W \subset S \backslash\{p\}$, we have $p \in S \backslash B \subset V \subset U$. Therefore $p$ is marginal in $S$ and hence peripheral in $S$ [8, Th. 1.8].

CoRollary 2.2. Let $L$ be a compact, connected topological lattice of finite codimension. If $p \in L$ is not a cutpoint of $L$ and $p$ is either meet irreducible or join irreducible, then $p$ is marginal in $L$.

Proof. Since $L$ is compact and connected, its breadth is equal to its codimension [7, Cor. 2.4]. Hence $L$ is a Lawson semilattice with respect to either $\vee$ or $\wedge$ [7, Th. 1.1]. Finally, $L$ is locally connected [1, Th. 2]; therefore the conclusion follows from Theorem 2.1.

Peripheral elements need not belong to $(M I(L) \cup J I(L))^{*}$. Examples may be found in $I^{3}$, the unit cube.

THEOREM 2.3. Let $S$ be a compact, connected, locally connected topological semilattice with 1 . If $p \in S$ and $M(p)^{\circ}=\varnothing$, then $M(p)$ is contained in the set of peripheral elements of $L$.

Proof. We define $F: S \times S \rightarrow S$ by $F(x, y)=x \wedge y$ for all $x, y \in S$. Then $F$ is continuous and $F(1, x)=x$ for all $x \in S$. If $s \in M(p)$ and $s$ is an inner point of $S$, then there exists an open set $U$ containing 1 such that for each $u \in U$ there is a $v \in S$ with $u \wedge v=$ $s$ [8, Th. 3.4]. This implies $U \subset M(s) \subset M(p)$ so that $M(p)^{\circ} \neq \varnothing$ contrary to hypothesis. Thus $s$ is peripheral in $S$; since $s$ was an 
arbitrary element of $M(p), M(p)$ consists entirely of peripheral elements of $S$.

As noted above a compact, connected topological lattice $L$ is locally connected and has a 1 ; thus if $M(p)^{\circ}=\varnothing$ in such a lattice, then $M(p)$ consists of peripheral elements of $L$.

The set of peripheral elements of a topological space need not be closed [8, p. 261]. However, we have the following.

COROLLARY 2.4. Let $L$ be a compact, connected topological lattice of finite codimension. If $A=\left\{x \in L: M(x)^{\circ}=\varnothing\right\}$, then each element of $A^{*}$ is peripheral in $L$.

Proof. Let $x \in A^{*}$ and suppose that $x$ is an inner point of $L$. Let $\left\{x_{\alpha}\right\}$ be a net in $A$ which converges to $x$. Then $\left\{x_{\alpha} \vee x\right\}$ also converges to $x$, and since $M\left(x_{\alpha} \vee x\right) \subset M\left(x_{\alpha}\right)$, we must have

$$
M\left(x_{\alpha} \vee x\right)^{\circ}=\varnothing \text {. }
$$

Thus $\left\{x_{\alpha} \vee x\right\} \subset A$. By Theorem 2.3 and our assumption that $x$ is inner, $M(x)^{\circ} \neq \varnothing$. Since the codimension of $L$ is finite we may choose an inner point $y$ of $L$ such that $y \in M(x)^{\circ}[8, \mathrm{Th} .2 .6]$; thus $y$ is also an inner point of $M(x)$ [8, Th. 1.4]. Since $x$ is the zero of $M(x)$ and $y$ is inner in $M(x)$, it follows from the proof of Thorem 2.3 that there must be an open subset $U$ of $M(x)$ which contains $x$ and such that $u \in U$ implies $u \leqslant y$. The net $\left\{x_{\alpha} \vee x\right\}$ converges to $x$ and $\left\{x_{\alpha} \vee x\right\} \subset M(x)$; therefore there exists an $\alpha$ such that $x_{\alpha} \vee x \in U$. Hence $x_{\alpha} \vee x \leqslant y$; therefore $y \in M\left(x_{\alpha} \vee x\right)$ which implies

$$
M(y) \subset M\left(x_{\alpha} \vee x\right) .
$$

But $M(y)^{\circ} \subset M(y) \subset M\left(x_{\alpha} \vee x\right)$ and $M(y)^{\circ} \neq \varnothing$ since $y$ is an inner point of $L$. Thus $M\left(x_{\alpha} \vee x\right)^{\circ} \neq \varnothing$ contrary to $x_{\alpha} \vee x \in A$. This contradiction completes the proof.

The set $A^{*}$ of Corollary 2.4 has some interesting properties not necessarily held by either the set of all peripheral elements or by the set of all meet irreducible elements of a lattice.

Proposition 2.5. Let $L$ and $A^{*}$ be as in Corollary 2.4.

(1) $x \leqslant y$ and $x \in A^{*}$ imply $y \in A^{*}$.

(2) $A^{*}$ is connected.

(3) If the breadth of $L, b(L)$, is two then $A^{*}$ consists of meet irreducible elements of $L$.

(4) If $b(L)=2$ and $w(M I(L))=n$, then $A^{*}$ is the union of at most $n$ compact, connected chains. 
(5) If $A^{*}$ is a sublattice of $L$, then $A^{*}=M\left(\Lambda A^{*}\right)$ and $b\left(A^{*}\right)=$ $c d\left(A^{*}\right)<b(L)=c d(L)$.

Proof. (1) Clearly $A$ is an increasing set; hence $A^{*}$ is also.

(2) For each $x \in A^{*}, M(x)$ is a connected subset of $A^{*}$ which contains 1 . Thus $A^{*}$ is connected.

(3) Let $x \in A^{*}$. Since $M(x) \subset A^{*}$ and $b(L)=2, \quad b(M(x))=$ $c d(M(x))=1$ [8, Th. 3.2]. Thus $x=a \wedge b$ implies $x=a$ or $x=b$.

(4) Since $A^{*} \subset M I(L), w\left(A^{*}\right) \leqslant n$. Hence by Dilworth's theorem [5, Th. 1.1], $A^{*}$ is the union of $n$ or fewer chains. These chains may be chosen to be compact and connected.

(5) If $A^{*}$ is a sublattice of $L$, then $z=\Lambda A^{*}$ belongs to $A^{*}$ and $A^{*}=M(z)$. As noted above $b\left(A^{*}\right)=c d\left(A^{*}\right)<c d(L)=b(L)$.

If $b(L)>2$, then $M(x) \subset A^{*}$ need not imply $M(x)$ is a chain; examples may be found in $I^{3}$, the unit cube.

Let $L=I^{2} \backslash\{(x, y): 0 \leqslant x<1 / 4,3 / 4<y \leqslant 1\}$. Then $L$ is a compact, connected, distributive topological lattice of breadth two and $A^{*}$ is a proper subset of $M I(L)$.

EXAMPLE 2.6. Let

$$
L=\left\{\left(x_{i}\right): 0 \leqslant x_{i} \leqslant 1\right\} \cup\left\{\left(x_{i}\right):-1 \leqslant x_{i} \leqslant 0\right\} \subset \prod_{i=1}^{\infty} R_{i},
$$

$R_{i}$ the set of real numbers for $i=1,2, \cdots$. With the order and topology inherited from $\prod_{i=1}^{\infty} R_{i}$, i.e., $\left(x_{i}\right) \leqslant\left(y_{i}\right)$ if and only if $x_{i} \leqslant y_{i}$ for $i=1,2, \cdots, L$ is a compact, connected topological lattice. Since $p=\left(p_{i}\right)$ with $p_{i}=0$ for $i=1,2, \cdots$ is a cutpoint of $L, p$ is an inner point of $L$. Any $\left(x_{i}\right) \in L$ with $0<x_{i} \leqslant 1$ for infinitely many $i$ has the property that $M\left(\left(x_{i}\right)\right)^{\circ}$ is empty. Thus

$$
p \in\left\{\left(x_{i}\right): M\left(\left(x_{i}\right)\right)^{\circ}=\varnothing\right\}^{*} .
$$

THEOREM 2.7. Let $L$ be a compact, connected topological lattice. If $a, b \in L$ and $a$ is a meet complement for $b$, then $[0, a]$ and $[0, b]$ are contained in the set of peripheral elements of $L$.

Proof. We define $F: L \times L \rightarrow L$ by $F(x, y)=x \vee y$ for all $x, y \in L$. Then $F$ is continuous and $F(0, y)=y$ for all $y \in L$. Let $x \in(0, a]=[0, a] \backslash\{0\}$; then $x \wedge b \leqslant a \wedge b=0$ which implies $x \wedge b=0$. If $x$ is not peripheral in $L$, then there exists an open set $U$ containing 0 such that for each $s \in U$ there is a $t \in L$ for which $s \vee t=x$ [8, Th. 3.4]. Since $[0, b]=b \wedge L$, it is connected; thus $U \cap(0, b] \neq \varnothing$. Let $s \in U \cap(0, b]$ and let $t \in L$ be such that $s \vee t=x$. Then $s \leqslant x$ and $s \leqslant b$; thus $s \leqslant x \wedge b=0$ which implies $s=0$ contrary to 
$s \in(0, b]$. Hence $x$ is peripheral in $L$. That 0 is peripheral is a consequence of Theorem 2.3. Thus each element of $[0, a]$ is peripheral in $L$. The proof for $[0, b]$ is similar.

The following corollaries are immediate.

CoROLlARY 2.8. Let $L$ be a compact, connected topological lattice. If $a, b \in L$ are not related, then $[a, a \vee b],[b, a \vee b],[a \wedge b, a]$, and $[a \wedge b, b]$ are contained in the set of peripheral elements of

$$
[a \wedge b, a \vee b]
$$

CoROLlaRY 2.9. Let $L$ be a compact, connected topological lattice. If for $p \in L$ there is a $q \in L$ such that $q$ is not related to $p$ and either $p \in M(p \wedge q)^{\circ}$, or $p \in L(p \vee q)^{\circ}$, then $p$ is peripheral in $L$.

3. Questions. 3.1. It is known [8, Ex. 1.9] that peripheral elements of topological spaces need not be marginal. Is this true for compact, connected lattices?

3.2. If $B$ is the set of all peripheral (marginal) elements of a compact lattice $L$, is $B$ closed in $L$ ?

\section{REFERENCES}

1. L. W. Anderson, On the distributivity and simple connectivity of plane topological lattices, Trans. Amer. Math. Soc., 91 (1959), 102-112.

2. K. A. Baker and A. R. Stralka, Compact, distributive lattices of finite breadth, Pacific J. Math., 34 (1970), 311-320.

3. G. Birkhoff, Lattice Theory, 3rd ed., Amer. Math. Soc. Colloq. Publ., vol. 25, Amer. Math. Soc., Providence, R. I., 1967.

4. H. Cohen, A cohomological definition of dimension for locally compact Hausdorff spaces, Duke Math. J., 21 (1954), 209-224.

5. R. P. Dilworth, A decomposition theorem for partially ordered sets, Ann. of Math.,

(2) 51 (1950), 161-162.

6. J. D. Lawson, Topological semilattices with small semilattices, J. London Math. Soc., 1 (1969), 719-724.

7. - The relation of breadth and codimension in topological semilattices II, Duke Math. J., 38 (1971), 555-559.

8. J. D. Lawson and B. Madison, Peripheral and inner points, Fundamenta Mathematicae, 69 (1970), 253-266.

9. — Peripherality in semigroups, Semigroup Forum, 1 (1970), 128-142.

10. J. W. Lea, Jr., An embedding theorem for compact semilattices, Proc. Amer. Math. Soc., 34 (1972), 325-331.

11. E. H. Spanier, Cohomology theory for general spaces, Ann. of Math., 49 (1948), 407-427.

12. A. D. Wallace, The peripheral character of central elements of a lattice, Proc. Amer. Math. Soc., 8 (1957), 596-597.

13. - Acyclicity of compact connected semigroups, Fundamenta Mathematicae, 50 (1961), 99-105. 
14. G. T. Whyburn, Analytic Topology, Amer. Math. Soc. Colloq. Publ., vol. 28, Amer. Math. Soc., Providence, R. I., 1942.

Received November 4, 1971 and in revised form October 5, 1972. A major part of this paper consists of a portion of the author's dissertation presented to the Graduate School of the Louisiana State University and directed by Professor J. D. Lawson.

Middle Tennessee State University 


\section{PACIFIC JOURNAL OF MATHEMATICS}

\section{EDITORS}

\author{
H. SAMELson \\ Stanford University \\ Stanford, California 94305 \\ C. R. HоввY \\ University of Washington \\ Seattle, Washington 98105
}

J. DugundJI

Department of Mathematics

University of Southern California

Los Angeles, California 90007

RICHARD ARENS

University of California

Los Angeles, California 90024

\section{ASSOCIATE EDITORS}
E. F. BeCKENBACH
B. H. NEUMANN
F. WOLF
K. YoshidA

\section{SUPPORTING INSTITUTIONS}

UNIVERSITY OF BRITISH COLUMBIA

CALIFORNIA INSTITUTE OF TECHNOLOGY

UNIVERSITY OF CALIFORNIA

MONTANA STATE UNIVERSITY

UNIVERSITY OF NEVADA

NEW MEXICO STATE UNIVERSITY

OREGON STATE UNIVERSITY

UNIVERSITY OF OREGON

OSAKA UNIVERSITY

\author{
UNIVERSITY OF SOUTHERN CALIFORNIA \\ STANFORD UNIVERSITY \\ UNIVERSITY OF TOKYO \\ UNIVERSITY OF UTAH \\ WASHINGTON STATE UNIVERSITY \\ UNIVERSITY OF WASHINGTON

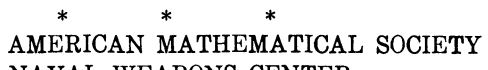 \\ NAVAL WEAPONS CENTER
}

The Supporting Institutions listed above contribute to the cost of publication of this Journal, but they are not owners or publishers and have no responsibility for its content or policies.

Mathematical papers intended for publication in the Pacific Journal of Mathematics should be in typed form or offset-reproduced, (not dittoed), double spaced with large margins. Underline Greek letters in red, German in green, and script in blue. The first paragraph or two must be capable of being used separately as a synopsis of the entire paper. The editorial "we" must not be used in the synopsis, and items of the bibliography should not be cited there unless absolutely necessary, in which case they must be identified by author and Journal, rather than by item number. Manuscripts, in duplicate if possible, may be sent to any one of the four editors. Please classify according to the scheme of Math. Rev. Index to Vol. 39. All other communications to the editors should be addressed to the managing editor, Richard Arens, University of California, Los Angeles, California, 90024.

50 reprints are provided free for each article; additional copies may be obtained at cost in multiples of 50 .

The Pacific Journal of Mathematics is issued monthly as of January 1966. Regular subscription rate: $\$ 48.00$ a year (6 Vols., 12 issues). Special rate: $\$ 24.00$ a year to individual members of supporting institutions.

Subscriptions, orders for back numbers, and changes of address should be sent to Pacific Journal of Mathematics, 103 Highland Boulevard, Berkeley, California, 94708.

PUBLISHED BY PACIFIC JOURNAL OF MATHEMATICS, A NON-PROFIT CORPORATION

Printed at Kokusai Bunken Insatsusha (International Academic Printing Co., Ltd.), 270, 3-chome Totsuka-cho, Shinjuku-ku, Tokyo 160, Japan. 


\section{Pacific Journal of Mathematics}

\section{Vol. 45, No. $2 \quad$ October, 1973}

Kenneth Paul Baclawski and Kenneth Kapp, Induced topologies for quasigroups and loops ............................................. 393

D. G. Bourgin, Fixed point and $\min -\max$ theorems $\ldots \ldots \ldots \ldots \ldots \ldots \ldots$

J. L. Brenner, Zolotarev's theorem on the Legendre symbol ............... 413

Jospeh Atkins Childress, Jr., Restricting isotopies of spheres .............. 415

John Edward Coury, Some results on lacunary Walsh series ................ 419

James B. Derr and N. P. Mukherjee, Generalized Sylow tower groups. II . . . . . . 427

Paul Frazier Duvall, Jr., Peter Fletcher and Robert Allen McCoy, Isotopy Galois

spaces .......................................... 435

Mary Rodriguez Embry, Strictly cyclic operator algebras on a Banach space ... 443

Abi (Abiadbollah) Fattahi, On generalizations of Sylow tower groups ......... 453

Burton I. Fein and Murray M. Schacher, Maximal subfields of tensor products . . 479

Ervin Fried and J. Sichler, Homomorphisms of commutative rings with unit

element .......................................... 485

Kenneth R. Goodearl, Essential products of nonsingular rings ............. 493

George Grätzer, Bjarni Jónsson and H. Lakser, The amalgamation property in

equational classes of modular lattices ...........................

507

$\mathrm{H}$. Groemer, On some mean values associated with a randomly selected simplex

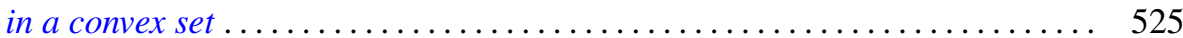

Marcel Herzog, Central 2-Sylow intersections .................... 535

Joel Saul Hillel, On the number of type-k translation-invariant groups ........ 539

Ronald Brian Kirk, A note on the Mackey topology for $\left(C^{b}(X)^{*}, C^{b}(X)\right) \ldots \ldots .543$

J. W. Lea, The peripherality of irreducible elements of lattice.............. 555

John Stewart Locker, Self-adjointness for multi-point differential operators ..... 561

Robert Patrick Martineau, Splitting of group representations ............... 571

Robert Massagli, On a new radical in a topological ring ................. 577

James Murdoch McPherson, Wild arcs in three-space. I. Families of Fox-Artin

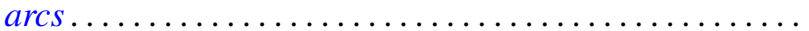

585

James Murdoch McPherson, Wild arcs in three-space. III. An invariant of

oriented local type for exceptional arcs . . . . . . . . . . . . ............ 599

Fred Richman, The constructive theory of countable abelian p-groups ........ 621

Edward Barry Saff and J. L. Walsh, On the convergence of rational functions

which interpolate in the roots of unity ..................

Harold Eugene Schlais, Non-aposyndesis and non-hereditary

decomposability..................................... 643

Mark Lawrence Teply, A class of divisible modules................... 653

Edward Joseph Tully, Jr., H-commutative semigroups in which each

homomorphism is uniquely determined by its kernel ................. 669

Garth William Warner, Jr., Zeta functions on the real general linear group ...... 681

Keith Yale, Cocyles with range $\{ \pm 1\} \ldots \ldots \ldots \ldots \ldots \ldots \ldots \ldots \ldots \ldots \ldots \ldots \ldots . \ldots \ldots$

Chi-Lin Yen, On the rest points of a nonlinear nonexpansive semigroup ........ 699 